RESEARCH REPORT

\title{
PATIENTS' PERCEPTIONS AND BELIEFS CONTRIBUTING TO NON-INTENTION TO ATTEND CARDIAC REHABILITATION PROGRAM: A LOCAL PERSPECTIVE
}

\begin{abstract}
OBJECTIVE

This study aimed to explore the perceptions and beliefs of patients contributing to non-intention to attend Cardiac Rehabilitation (CR). METHODS

A cross-sectional study in which a total number of 148 voluntary patients were enrolled to local CR programs for the research. Purposive sampling method was used and the data was collected in 6 months. A structured questionnaire was used to collect data regarding socio-demographic characteristics and patients' beliefs and perceptions related to non-intention to attend CR.

\section{RESULTS}

$64.8 \%$ of the 148 patients had intended to attend CR and mean age $( \pm$ SD) of patients was 54.8 ( \pm 12.3 ) years with $64.9 \%$ males. For categorical variables, Spearman Correlation test was used in which patients' intention to attend CR was significantly associated with ethnicity $(P<0.01)$, patient diagnosis and procedure $(P<0.001)$ and residential area $(P<0.001)$. Conversely, no association has been found between gender, age, educational status, and the use of tobacco with the patients' intentions for CR. Misconceptions about CR were identified as the key barriers for non-intention to attend CR. These findings reflected patients' lack of knowledge about CR course content (55.8\%), misperceptions that exercise should be avoided to prevent fatigue in cardiac patients (71.2\%), walking on treadmill would be more difficult than walking on floor (67.3\%) and uncertainty about the suitability and necessity of exercise for their personal mode of heart disease (40.4\%). Moreover, other barriers reported were transport difficulties $(73.1 \%)$, unavailability of attendants to accompany (25\%), and work responsibilities (17.3\%).

\section{CONCLUSIONS}

Lack of knowledge about CR benefits and misperceptions about personal suitability are reported to as key barriers. Comprehensive information delivery about the benefits of $C R$, motivation and endorsement by the physician to attend CR programs and accessibility of CR sites nearby residence could be used to address barriers in attending $C R$.
\end{abstract}

\section{KEYWORDS}

beliefs, cardiac rehabilitation, coronary heart disease, perceptions, intentions, non-attendance

\section{Dr. Farzana Amir Hashmi} Deputy General Manager, HOD Preventive Cardiology and Cardiac Rehabilitation Tabba Heart Institute farzana.hashmi@tabbaheart.org

\section{Marium Sheikh}

Sr. Therapeutic Dietitian Department of Preventive Cardiology and Cardiac Rehabilitation

Tabba Heart Institute mariam.sheikh@tabbaheart.org

\section{Faraz lqbal Tipu}

Rehab Specialist

Department of Preventive

Cardiology and Cardiac Rehabilitation

Tabba Heart Institute

faraz.tipu@ymail.com

[Hashmi FA, Sheikh M, Tipu FI Patients' perceptions and beliefs contributing to non-intention to attend cardiac rehabilitation program: a local perspective. Pak. j. rehabil. 2016;5(1):11-17] 


\section{INTRODUCTION}

The epidemic of cardiovascular disease (CVD) is a global phenomenon'. As the $21^{\text {st }}$ century proceeds, it is clear that CVD has become a pervasive and entrenched cause of morbidity and a leading contributor to mortality making it the number one cause of deaths globally'. It is estimated that CVDs account for about 17.5 million deaths in 2012 (i.e. $31 \%$ of all global deaths). Furthermore, it is not surprising that CVD related mortality is higher than all forms of cancers combined ${ }^{2}$. Among these deaths, 7.4 million attributed to coronary heart disease (CHD) and 6.7 million attributed to stroke. The American Heart Association (AHA) projects this number to grow to greater than 23.6 million by $2030^{3}$.

Moreover, among developed and developing nations, CVD related mortality rates and patterns are different. In developed countries, CVD related mortality accounts for about $38 \%^{4}$. CVD as a number one killer results in over 4 million deaths in Europe and over 1.9 million deaths in European Union (EU) every year ${ }^{5}$. In United States (US), the total number of yearly mortality is about 610,000 people i.e. 1 in every 4 deaths $^{6}$.

However, the rate of CVD deaths in low and middle-income countries is $28 \%$, which accounts for three fourth of the global death toll ${ }^{4}$. For the last decade, the presentation of classical CVD risk factors in the developing world (including, India and China) is increasing. Substantially, there is also a constant increase in the coronary and cerebrovascular events in these countries. It is projected that in 2020 CVD will become the major cause of morbidity and mortality in the developing nations as well7.

As a result of epidemiological transition, during the last decade the burden of non-communicable diseases (NCDs) such as cardiovascular diseases, including stroke and heart diseases, cancers, diabetes, mental disorders and chronic obstructive pulmonary diseases (COPD) have been increased in Pakistan. It is a grave fact that each day 2000 Pakistanis lose their lives from this preventable menace $^{8}$.

According to the United Nations (UN) report these so-called "lifestyle diseases" could cost Pakistan nearly US $\$ 300$ million in 2025. The epidemic of NCDs have taken per capita health expenditure to 36.11 US \$ in 2014, which is nearly unbearable for the $12.5 \%$ of total population that are living below the national poverty line according to the World Bank ${ }^{3}$. Globally, the total healthcare cost related to CVDs is greater than $\$ 320.1$ billion?.

Modifiable risk factors for CVDs, that can be treated or changed, include hypertension, diabetes, hypercholesteremia, overweight or obesity, sedentary lifestyle, nutrients deficiency, energy dense diet, tobacco use and alcohol intake ${ }^{10}$. Corrective measures to these factors can improve efficacy of preventing CVD related morbidity and mortality over three quarters of the present statistics ${ }^{11}$.

Hospital Cardiac Rehabilitation (HCR) is a multidisciplinary program that can help improve life quality after CVD events as well as it can also help to prevent recurrence of such episodes. The program consists of physical activity counseling and training, education on managing risk factors and reducing stress. Recent guidelines of American Heart Association (AHA) and the American College of Cardiology Foundation (ACCF) related to the management and prevalence of CHD provides a Class I-level recommendation for referral to CR programs ${ }^{12}$.

The promising benefits of cardiac rehabilitation include reductions in morbidity and mortality, increased exercise tolerance and improved quality of life and psychological wellbeing. These health benefits have been evident in several RCTs and meta-analyses ${ }^{11-14}$. A meta-analysis, conducted in Canada, showed that CR resulted in $17 \%$ reductions in myocardial infarction (MI) events at 12 months and $47 \%$ reductions in mortality rates at 24 months $^{15}$.

There is a suboptimal utilization of CR programs, despite of its robust evidence of therapeutic efficacy and improvements in psychosocial wellbeing ${ }^{14}$. Many studies proved decline in CR attendance among cardiac patients. In a study, only $34.7 \%$ of respondents who had experienced a heart attack attended outpatient cardiac rehabilitation ${ }^{16}$. In Canada, among 5886 subjects who underwent coronary angiography and referred to CR program only 2900 subjects (i.e. 49.3\%) completed the full duration of the CR program ${ }^{17}$. In European countries, the ratio of participation in formal rehabilitation program is as less as one third of total referred patients $^{18}$.

There is very limited availability of structured outpatient CR programs in middle income countries. And the attendance rate in these limited accessible CR programs is dismally low. A cross sectional study, conducted in a tertiary care hospital in Karachi, Pakistan showed that only $36.2 \%$ of 416 referred cardiac patients attended $\mathrm{CR}^{18}$. However, patient characteristics and contributing barriers to attend CR still need to be elucidated.

The barriers of underutilization of CR programs in middle income countries are reported to be unvarying with those in the high-income countries ${ }^{19}$. A systematic review of factors associated with poor utilization of CR programs reported barriers at three inter-connected levels i.e. patient level, provider level, and system level barriers ${ }^{20}$. The predominantly proclaimed patient-related CR barriers documented in present literature included older age, low 
socioeconomic status (SES), role obligations and subsequent time conflicts i.e. job timings inflexibility, fear of loss of salary, self-employment, lack of health insurance, patient disinterest, co morbidities, low education attainment, female sex, patients' beliefs about their illness, low self-efficacy and limited family and social support20-24. Physician should ensure the all potential candidates are referred to CR, before they get discharge from the hospital ${ }^{21}$.

At the health-system level, there are also many barriers to CR provision including limited availability of CR programs, lack of health insurance coverage ,poor patient-provider relationship, lack of programs availability at peripheral areas and low-income communities, long travel distance, limited or inflexible hours of operation, and gender-dominated programs ${ }^{24-25}$.

The decreasing attendance rate can prove the existence of factors that influence participation of patients in cardiac rehabilitation programs. Factors that are identified include poor referral or lack of physician reinforcement, limited follow up, lack of health insurance, job responsibilities, dependency on attendants, home or work priorities, poor accessibility and limited availability of structured outpatient programs, long distant centers, conveyance problems and unavailability of secure parking areas, lack of knowledge about CR benefits, lack of perceived need for rehabilitation, limited culturally diverse setups and gender-dominated programs. Therefore, surgical procedure is also a decisive factor in $\mathrm{CR}$ enrollment. Another study revealed that patients who undergone elective CABG surgery and who had easy access to the CR center had better attendance rates than their counterparts $^{23}$. Studies also concluded that non attendant participants have a limited understanding of $C R$ and its role in reducing their risks for future cardiac events ${ }^{23,24}$. Moreover, patients who underwent major cardiac surgery i.e. coronary artery bypass graft (CABG) had a better participation rate at CR compared to those with other cardiac diagnosis or less invasive procedures ${ }^{25}$.

In most countries, physician referral is the prerequisite step for CR participation. Studies have shown that lack of physician referral to $C R$ is the key barrier to optimal utilization of CR programs in developed nations ${ }^{23,25}$. Another barrier contributing to poor participation at CR is low SES.

Cardiac patients at 11 hospitals across Ontario were studied and it was found that patients with low SES had lower rates of $C R$ referral and enrollment when compared to patients with high SES.

In order to gain the maximum potential for prevention strategies, based on healthier lifestyle, increased physical activity, and appropriate management of classical cardiovascular risk factors, it is important to address the remaining gaps in the evidence. Moreover, the European Guidelines on Cardiovascular Disease Prevention in Clinical Practice - 2012 mentioned that the reasons for change in the behaviors of both populations and the people are incompletely understood and is still required to be explored. Hence, there is a greater need to clearly apprehend the reasons for poor uptake of CR in the local scenario. This would eventually help to gain deeper insights for formulating better policies and designing appropriate strategies to achieve long-lasting sustainable impacts in combating the 'Greatest Mankind Epidemic.'

Moreover, to best of our knowledge, no significant studies have been conducted in our country which explored the barriers contributing to non-intention to attend CR programs. Therefore, the present study aimed to explore the perceptions and beliefs of patients contributing to non-intention to attend CR.

\section{METHODOLOGY}

A cross-sectional study was conducted at Tabba Heart Institute (THI) to investigate factors associated with CR attendance. THI is located in Karachi which is a private tertiary care hospital, and it provides cardiac care to a mixture of people from low to high income strata. Moreover, THI is a state-of-the-art cardiac hospital which is the only set up in the city that offers supervised cardiac rehabilitation program. The Preventive Cardiology and Cardiac Rehabilitation Department at THI provides tailored CR program based on American Heart Association (AHA) and American College of Sports Medicine (ASCM) recommendations, which is a minimum of 2 sessions per week, for 9 weeks or preferably 3 sessions per week, for 6 weeks with supervised exercise, cardiac education and diet consultation. CR team is designed by keeping in view a multi-disciplinary approach which included dietitian, physiotherapists trained for $C R$, cardiac nurses, diabetes educator and other allied health professionals, working in close coordination with cardiologists/cardiac surgeons.

Selection of participants for the study was based on referred or eligible patients during the defined period of data collection. The patients were invited to participate in the study by the concerned CR staff, prior to hospital discharge. Patients who had sustained a cardiac event, suffered from acute coronary syndrome (ACS) or undergone any cardiac surgery were considered eligible for the study. Patients were not included in the study who did not give consent, not in a stable state of mind, suffered with any functional impairment, in which exercise was contraindicated or who suffered from a life-threatening significant morbidity for-example, terminal cancer.

A total number of 150 voluntary patients ( $>18$ years) 
who were referred or eligible to CR program were enrolled for the research. The sampling method was purposive. All details of eligible patients were logged by CR staff as data collectors either enrolling or refusing for $C R$ programs. A detailed questionnaire was used to collect socio-demographic characteristics and patients' perceived suitability, benefits and barriers to CR programs.

The data collection took place between August, 2014 and January, 2015. The CR coordinator provided patients with information about the structure of CR program including the duration, session length, fee structure and the services that would be included as well as the inclusion criteria (e.g. Acute Myocardial Infarction (AMI), Permanent Pace Maker (PPM), Percutaneous Coronary Intervention (PCI), Coronary Artery Bypass Graft (CABG), Percutaneous Trans venous Mitral Commissurotomy (PTMC) and valve replacement surgeries). Informed consent was obtained from patients and their decision makers (e.g. husband, father or son), especially in the case of female patients to be culturally sensitive and adapt local values. The data analysis was performed using SPSS (Statistical Package for Social Sciences), Version 16. Age was computed as mean \pm SD. Percentages and frequencies were calculated for continuous variables. Spearman correlation test was computed to test association between categorical variables. A value of $\mathrm{P}<0.05$ was considered statistically significant.

\section{RESULTS}

$64.8 \%$ of the 148 patients stated that they intended to attend $C R$. The mean age ( \pm SD) of patients was 54.88 ( \pm 12.3 ) years and $64.9 \%$ were males. For categorical variables, Spearman Correlation test was used to assess the association between intention to attend CR and the patients' characteristics. Patients' intention to attend CR was significantly associated with ethnicity ( $r s .235, \mathrm{P}<0.01$ ), patient diagnosis and procedure ( $r$ s .551, $\mathrm{P}<0.001$ ) and residential area (rs .309, $\mathrm{P}<0.001$ ). Conversely, no association has been found between gender, age, educational status, and the use of tobacco with the patients' intentions to opt CR services. Majority of the patients who have undergone Coronary Artery
Bypass Graft (CABG) surgery have shown their intention to attend CR. Furthermore, above $90 \%$ of the patients dwelling in Karachi were also willing to attend rehabilitation services.

\begin{tabular}{|c|c|c|c|}
\hline \multicolumn{4}{|c|}{$\begin{array}{l}\text { Table 1: Association of Factors with Intention of patients to Attend Cardiac } \\
\text { Rehablitation }\end{array}$} \\
\hline Characteristics & $\begin{array}{l}\text { Intender Group } \\
\qquad \begin{array}{c}(\mathrm{N}=96) \\
\%(\mathrm{~N})\end{array}\end{array}$ & $\begin{array}{l}\text { Non-Intender Group } \\
(\mathrm{N}=52) \\
\%(\mathrm{~N})\end{array}$ & $r^{s}$ (p-value $)$ \\
\hline \multicolumn{3}{|l|}{ Gender } & $-0.01(0.86)$ \\
\hline Male & $63.5(61)$ & $67.3(35)$ & \\
\hline Female & $36.5(35)$ & $32.7(17)$ & \\
\hline \multicolumn{3}{|l|}{ Ethnicity } & $0.23(<0.01)$ \\
\hline Urdu Speaking & $72.9(70)$ & $50(26)$ & \\
\hline Sindhi & $9.4(9)$ & $13.5(7)$ & \\
\hline Balochi & $2.1(2)$ & $3.8(2)$ & \\
\hline Punjabi & $3.1(3)$ & $5.8(3)$ & \\
\hline Pathan & $3.1(3)$ & $5.8(3)$ & \\
\hline Memon & $3.1(3)$ & $9.6(5)$ & \\
\hline Hindu & ---- & $1.9(1)$ & \\
\hline Others* & $6.2(6)$ & $9.6(5)$ & \\
\hline \multicolumn{3}{|l|}{ Age Group } & $0.01(0.89)$ \\
\hline 49 years or less & $23.7(483)$ & $19.5(44)$ & \\
\hline $50-59$ years & $31.6(645)$ & $36.3(82)$ & \\
\hline $60-69$ years & $27.9(570)$ & $31.9(72)$ & \\
\hline 70 years or above & $16.8(343)$ & $12.4(28)$ & \\
\hline \multicolumn{3}{|l|}{ Education } & $-0.01(0.196)$ \\
\hline No Formal Eucation & $12.5(12)$ & $13.5(7)$ & \\
\hline Primary & $7.3(7)$ & $23.1(12)$ & \\
\hline Secondary & $10.4(10)$ & $5.8(3)$ & \\
\hline Matriculation & $16.7(16)$ & $19.2(10)$ & \\
\hline Intermediate & $22.9(22)$ & $9.6(5)$ & \\
\hline Graduation & $22.9(22)$ & $21.2(11)$ & \\
\hline Post Graduation & $7.3(7)$ & $7.7(4)$ & \\
\hline \multicolumn{3}{|l|}{ Use of Tobacco } & $-0.03(0.693)$ \\
\hline Current User & $24(23)$ & $26.9(14)$ & \\
\hline Non-User & $76(73)$ & $73.1(38)$ & \\
\hline \multicolumn{3}{|c|}{ Admitting Diagnosis and Procedures } & $0.55(<0.001)$ \\
\hline AMI & $3.1(3)$ & $38.2(2)$ & \\
\hline CABG & $78.1(75)$ & $17.3(9)$ & \\
\hline $\mathrm{PCl}$ & $10.4(10)$ & $25(13)$ & \\
\hline Angina & $5.2(5)$ & $50(26)$ & \\
\hline VR & $3.1(3)$ & $3.8(2)$ & \\
\hline \multicolumn{3}{|l|}{ Residence } & $0.30(<0.001)$ \\
\hline Karachi & $91.6(88)$ & $67.3(35)$ & \\
\hline Outside Karachi & $8.4(8)$ & $32.7(17)$ & \\
\hline
\end{tabular}


AMI indicates acute myocardial infarction; $C A B G$, coronary artery bypass graft surgery; CR, cardiac rehabilitation; $\mathrm{PCl}$, percutaneous coronary intervention; VR, valve repair/ replacement.

Among the non-intenders group, $50 \%$ of the patients with Angina refused to participate in CR program. The main reasons given for not intending to attend CR were the perceptions of exercise as tiring or painful and that the program would be difficult and unnecessary. Moreover, $73.1 \%$ of the non-intenders reported to have transport difficulties.
Among total patients (including intenders and non-intenders both), about $36.5 \%$ reported that they should take rest and avoid exertion after AMI, $\mathrm{PCl}$ and $\mathrm{CABG}$. Only $8.8 \%$ of the respondents reported that commitment to family responsibilities is a barrier to CR attendance with only $18.9 \%$ reported unavailability of attendants as a major hurdle to achieve optimum participation at CR. Moreover, a total of $55.8 \%$ patients were unaware of the CR course content

\begin{tabular}{|c|c|c|c|c|c|c|}
\hline \multirow[t]{2}{*}{ Patients Perception and Beliefs } & \multicolumn{3}{|c|}{$\begin{array}{l}\text { Intender Group } \\
\qquad(\mathrm{N}=96) \\
\%(\mathrm{~N})\end{array}$} & \multicolumn{3}{|c|}{$\begin{array}{l}\text { Non-Intender Group } \\
\qquad \begin{array}{l}(\mathrm{N}=52) \\
\%(\mathrm{~N})\end{array}\end{array}$} \\
\hline & Yes & No & Unsure & Yes & No & Unsure \\
\hline Exercise may be harmful to me & $13.5(13)$ & $75(72)$ & $11.5(11)$ & $7.7(4)$ & $88.5(46)$ & $3.8(2)$ \\
\hline $\begin{array}{l}\text { I should rest and avoid physical extention } \\
\text { after } A M / C A B G / P C l\end{array}$ & $41.7(40)$ & $46.9(45)$ & $11.5(11)$ & $26.9(14)$ & $67.3(35)$ & $5.8(3)$ \\
\hline I should avoid exercise if i feel tired & $66.7(64)$ & $19.8(19)$ & $13.5(13)$ & $71.2(37)$ & $23.1(12)$ & $5.8(3)$ \\
\hline $\begin{array}{l}\text { CR would involve mainly physical exercise } \\
\text { and is only appropiate for patients who were } \\
\text { previously fit }\end{array}$ & $36.5(35)$ & $14.6(14)$ & $49(47)$ & $9.6(5)$ & $55.8(29)$ & $34.6(18)$ \\
\hline $\begin{array}{l}\text { Walking on treadmill is dificult that walking } \\
\text { on floor }\end{array}$ & $39.6(38)$ & $46.9(45)$ & $13.5(13)$ & $67.3(35)$ & $25(13)$ & $7.7(4)$ \\
\hline My job is a barrier to attend $C R$ & $21.9(21)$ & $75(71)$ & $3.1(3)$ & $17.3(9)$ & $53.8(28)$ & $28.8(15)$ \\
\hline I have transport difficulties & $28.1(27)$ & $67.7(65)$ & $4.2(4)$ & $73.1(38)$ & $25(13)$ & $1.9(1)$ \\
\hline $\begin{array}{l}\text { I have commitment to my family } \\
\text { responsibilities }\end{array}$ & $10.4(10)$ & $81.2(78)$ & $8.3(8)$ & $5.8(3)$ & $67.3(35)$ & $26.9(14)$ \\
\hline $\begin{array}{l}\text { Attendance are not avaliable to accompany } \\
\text { at CR services }\end{array}$ & $15.8(15)$ & $75.8(72)$ & $8.4(8)$ & $25(13)$ & $50(26)$ & $25(13)$ \\
\hline$C R$ is a necessary part of my treatment & $96.9(93)$ & $3.1(3)$ & & $92.3(48)$ & $7.7(4)$ & \\
\hline $\begin{array}{l}\text { CR is unnecessary, espacially to my personal } \\
\text { mode of heart attact }\end{array}$ & $7.3(7)$ & $38.5(37)$ & $54.2(52)$ & $11.5(6)$ & $48.1(25)$ & $40.4(21)$ \\
\hline I am aware of the CR course content & $67.7(65)$ & $17.7(17)$ & $14.6(14)$ & $38.5(20)$ & $55.8(29)$ & $5.8(3)$ \\
\hline $\begin{array}{l}\text { Participation at } C R \text { would enable me to } \\
\text { return to work early }\end{array}$ & $95.8(92)$ & $2.1(2)$ & $2.1(2)$ & $86.5(45)$ & $3.8(2)$ & $9.6(5)$ \\
\hline I really need to improve my fitness level & $80.2(77)$ & $13.5(13)$ & $6.2(6)$ & $80.8(42)$ & $9.6(5)$ & $9.6(5)$ \\
\hline I would recommend CR to others & $99(95)$ & & $1(1)$ & $88.5(46)$ & $1.9(1)$ & $9.6(5)$ \\
\hline
\end{tabular}




\section{DISCUSSION}

We aimed to develop a sound evaluation of patient's beliefs regarding $C R$ after sustaining a cardiac event, suffering from acute coronary syndrome (ACS) or undergoing any cardiac surgery and ascertain the association between such beliefs, perceptions and participation rates at the CR program. Results obtained from the current study demonstrated that in consistent to previous observations, the number of attendees intending to join the CR amongst eligible patients is relatively low ${ }^{10,16}$ making it $65 \%$ in the observed study.

Factors that had no association with patient's intention regarding $C R$ services were gender, age, educational status, and the use of tobacco. This contradicts many of the studies where these factors were considered as major barriers in CR attendance. However, these differences in our results are possibly due to the fact that in the present study we only considered patients' intention to participate in $\mathrm{CR}$ and not the actual attendance rate.

Cultural and ethnic differences have been shown to be the major detrimental factors of underused rehabilitation services. It is noteworthy that majority of ethnic groups who have shown significant intention to attend CR were Urdu Speaking (72.9\%) and Sindhi $(9.4 \%)$. These findings strongly support the conclusion drawn from a study done to assess the hierarchy of multiple barriers to participation in cardiac rehabilitation and preventive program in Israel, where ethnicity was considered to be a salient predictor of enrollment in CR programs. Therefore, with the goal of increasing participation, considerable efforts need to be expanded to use patient and cultural specific CR programming to reduce potential cultural and ethnic barriers.

Perceptions about course content and effectiveness of CR were found to be major factors amongst non-attendees in the current study. A total of $55.8 \%$ patients were unaware of the CR course content. Similarly, the strongest predictors of lifestyle changes following a cardiac event were found to be the perceived benefits associated with CR and perceptions related to self-efficacy. Comprehensive teaching related to the course and its effectiveness can prove to be a factor in increasing attendance rate of patients.

Role of referral status has been well documented in the available literature and according to the previous studies the variability in referral status was explained by the strength of physician endorsement of CR services and the poor screening of in-hospital healthcare team to refer potential candidates to the CR services. However, in the present study, $96.4 \%$ of eligible patients were referred to CR by their physician. Therefore, it can be inferred that the lack of reinforcement, limited provision to CR services and lack of accessibility are attributed to low attendance rate in our region.

Results of previous study have shown that AMl patients who viewed their medical condition as symptomatic, and with severe consequences were more likely to attend CR. Concurrently, in our study patients who have undergone CABG surgery are more intended to participate than those who had suffered angina and undergone $\mathrm{PCl}$. Our results are consistent with the previous studies, where it was found that CR uptake is higher after CABG surgery than with $\mathrm{AMl}$ not treated with revascularization procedures. Therefore, special attention needs to be directed towards Angina and $\mathrm{PCl}$ patients and comprehensive information should be delivered regarding the benefits and efficacy of $C R$ to their medical condition and quality of life.

\section{CONCLUSIONS}

Although patients' socio-demographic characteristics and clinical profile are significantly associated with their intention to attend CR programs, but the key barriers reported are the lack of knowledge about CR benefits, transport unavailability and ethnic background. Comprehensive information delivery about the benefits of $C R$, motivation and reinforcement by the physician to attend $C R$ programs and accessibility of $C R$ sites nearby residence could be used to address barriers in attending $C R$.

\section{REFERENCES}

[1] Gersh BJ, Sliwa K, Mayosi BM, Yusuf S. Novel therapeutic concepts: the epidemic of cardiovascular disease in the developing world, global implications. Eur Heart J. 2010;31 (6):642-648

[2] Liberty. Heart disease fact sheet. 2011;1-2. Available from: http://www.libertyfinancials. co.za/lib/content/images/newsbreak/LibCorpCustUpdate/pdf/201101_HeartDi seaseFactsheet.pdf

[3] Mozaffarian D, Benjamin E, Go A, Arnet D, Blaha $M$, Cushman $M$, et al. Heart disease and stroke statistics - at-a-glance heart disease, stroke and other cardiovascular diseases, heart disease, stroke and cardiovascular disease risk factors. Am Hear Assoc. 2015; (1):7-10

[4] Gaziano TA, Bitton A, Anand S, Abrahams-Gessel S, Murphy A. Growing epidemic of coronary heart disease in low- and middle- income countries. Currative Probl Cardiol. 2011;35(2):72-115

[5] Nichols $M$, Nick TPS. European cardiovascular disease statistics (European Heart Network). Eur Heart Net. 2012. P 10.

[6] Mozaffarian D, Benjamin EJ, Go AS, Arnett DK, Blaha MJ, Cushman M, et al. Heart disease and stroke statistics-2016 update a report from the American Heart Association. Circul. 
2016;133(4):38-48

[7] Celermajer DS, Chow CK, Marijon E, Anstey NM, Woo KS. Cardiovascular disease in the developing world: prevalence, patterns, and the potential of early disease detection. J Am Coll Cardiol. 2012;60(14):1207-1216

[8] Wasay $M$, Zaidi S, Khan M, Jooma R. Non communicable diseases in pakistan: burden, challenges and way forward for health care authorities. J Pak Med Assoc. 2014;64(11):1218-1219

[9] Mozaffarian D, Benjamin EJ, Go AS, Arnett DK, Blaha MJ, Cushman M, et al. Heart disease and stroke statistics -2015 updated. Circul. 2014; Available from: http://circ.ahajournals.org/content/early/2014/12/18/CIR.0000000000000152

[10] World Heart Federation. Cardiovascular disease risk factors [Internet]. Available from: http://www.world-heart-federation.org/cardiovascular-health/cardiovascular-disease-risk-factors

[11] American Heart Association. My Life Check Life's Simple [Internet]. Available from: http://www. heart.org/HEARTORG/Conditions/My-Life-Check---Lifes-Simple-7_UCM_4714 53_Article.jsp\#.WCH1ptV94dU

[12] Thomas RJ, King M, Lui K, Oldridge N, Pina IL, Spertus J. AACVPR/ACCF/AHA 2010 Update: performance measures on cardiac rehabilitation for referral to cardiac rehabilitation/secondary prevention services: a report of the American Association of Cardiovascular and Pulmonary Rehabilitation and the American College of Cardiology Foundation/American Heart Association Task Force on Performance Measures. Circul. 2010;122(13):1342-1350

[13] Anderson L, Oldridge N, Thompson DR, Zwisler AD, Rees K, Martin N. Exercise-Based Cardiac Rehabilitation for Coronary Heart Disease. J Am Coll Cardiol. 2016:67(1):1-12

[14] Goel K, Lennon RJ, Tilbury RT, Squires RW, Thomas RJ. Impact of cardiac rehabilitation on mortality and cardiovascular events after percutaneous coronary intervention in the community. Circul. 2011;123(21):2344-2352

[15] Taylor RS, Brown A, Ebrahim S, Jolliffe J, Noorani $\mathrm{H}$, Rees $\mathrm{K}$ et al. Exercise-based rehabilitation for patients with coronary heart disease: systematic review and meta-analysis of randomized controlled trials. Am J Med.
2004; $116(10): 682-692$

[16] Lawler P, Filion K, Eisenberg MLawler P, Filion K EM. Efficacy of exercise-based cardiac rehabilitation post-myocardial infarction: a systematic review and meta-analysis of randomized controlled trials. Am Heart J. 201 1;162:571-584

[17] Clark AM, Hartling L, Vandermeer B MF. Meta-analysis: secondary prevention programs for patients with coronary artery disease. 2005; 1 43(9):659-672

[18] Ali M, Qadir F, Javed S, Khan ZN, Asad S, Hanif B. Factors affecting outpatient cardiac rehabilitation attendance after acute myocardial infarction and coronary revascularization - a local experience. J Pak Med Assoc. 2012;62(4):347-351

[19] Martin BJ, Haver T, Arena R, Austford LD, Galbraith PD, Lewin AM, et al. Cardiac rehabilitation attendance and outcomes in coronary artery disease patients. Circul. 2012;126(6):677-687

[20] Seth A, Cui J, To E, Kwee M, Matsubara J. Complement-associated deposits in the human retina. Disabil Rehabil. 2008;49(2):743-750.

[21] Mampuya WM. Cardiac rehabilitation past, present and future: an overview. Cardiovasc Diagn Ther. 2012;2(1):38-49

[22] De Melo Ghisi GL, dos Santos RZ, Aranha EE, Nunes AD, Oh P, Benetti M, et al. Perceptions of barriers to cardiac rehabilitation use in Brazil. Vasc Health Risk Manag. 2013:9(1):485-491

[23] Murray J, Craigs CL, Hill KM, Honey S, House A. A systematic review of patient reported factors associated with uptake and completion of cardiovascular lifestyle behaviour change. Cardiovasc Disord. 2012;12(1):120.

[24] Balady GJ, Ades PA, Bittner VA, Franklin BA, Gordon NF, Thomas RJ, et al. Referral, enrollment, and delivery of cardiac rehabilitation/secondary prevention programs at clinical centers and beyond: a presidential advisory from the American Heart Association. Circul. $2011 ; 124(25): 2951-2960$

[25] Suaya JA, Shepard DS, Normand S-L, Ades PA, Prottas J, Stason WB. Use of cardiac rehabilitation by Medicare beneficiaries after myocardial infarction or coronary bypass surgery. Circul. 2007;1 16(15):1653-1662. 